\title{
Synonymy and the A Priori: A Problem for Boghossian's Model
}

[This is a pre-copyedited, author-produced version of an article accepted for publication in Analysis following peer review. The version of record (Nyseth, F. 2017. Synonymy and the a priori: A problem for Boghossian's model. Analysis 77: 559-565) is available online at: https://doi.org/10.1093/analys/anx114.

How is a priori knowledge possible? One prominent strategy for answering this question tries to do so by appealing to knowledge of language and meaning. The central idea is that knowing how to speak a certain language may suffice, in special cases, for knowing that certain sentences of the language - and the propositions they express - are true.1 Though such views are less popular than they were in the first half of the 20th century, they are not without advocates today. One prominent contemporary defender, Paul Boghossian, holds that some truths are knowable a priori because they are expressed by epistemically analytic sentences.2 In such cases, he says, grasping the meaning of the sentence may suffice for justified belief in the truth of the proposition it expresses $(2003,15)$.

One alleged route from understanding to justification goes via what

\footnotetext{
${ }^{1}$ Or at least assertible, since some advocates of this strategy deny that a priori truths are, strictly speaking, truths (see, e.g., Ayer 1936b, where Ayer modifies the view he had advocated, shortly before, in Ayer 1936a).

${ }^{2}$ Boghossian presents this view in a number of places, notably in Boghossian 1996, and Boghossian 2003
} 
Boghossian calls 'the synonymy model'. I will argue that this model is inadequate. First, I articulate a simple dilemma which shows that the model, as initially formulated, is incapable of explaining how synonymy could provide a route to a priori knowledge. Second, I argue that while a potential strategy for avoiding the dilemma is available, this does not vindicate Boghossian's model; rather, it reveals that a different model is needed.

The synonymy model takes the form of a piece of reasoning which is supposed to explain how the reasoner could come to know the conclusion a priori. Here is Boghossian's illustration of it using a well-worn example:

1. 'All bachelors are unmarried males' means that All bachelors are unmarried males. (By knowledge of S's meaning) ${ }^{3}$

2. Since 'bachelor' just means 'unmarried male', 'All bachelors are unmarried males' is synonymous with 'All unmarried males are unmarried males'. (By understanding of meaning).

3. 'All unmarried males are unmarried males' means that All unmarried males are unmarried males. (By knowledge of S's meaning) $4^{\mathbb{4}}$

4. If sentence $\mathrm{F}$ is synonymous with sentence $\mathrm{G}$, then $\mathrm{F}$ is true iff $\mathrm{G}$ is true. (Conceptual knowledge of the link between meaning and truth).

5. Therefore, 'All bachelors are unmarried males' is true iff All unmarried males are unmarried males.

6. All unmarried males are unmarried males. (By knowledge of logic).

7. Therefore, 'All bachelors are unmarried males' is true.

8. Therefore, All bachelors are unmarried males. (Boghossian 2003, 18)

\footnotetext{
${ }^{3} \mathrm{~S}$ being the sentence in question.

${ }^{4}$ Although Boghossian uses ' $\mathrm{S}$ ' here too, it is clear that this ' $\mathrm{S}$ ' is not that of step (1).
} 
This is, Boghossian tells us, 'a route from meaning to justification that philosophers have often had in mind, without bothering to spell it out' (2003, 18). He is well aware, of course, that it cannot be the complete story as to how a priori knowledge is possible. It assumes, after all, that we already have some a priori knowledge - notably, that we know some logi $5^{5}$ - and even if we set this aside, there is no reason to think that the model can be applied to all cases of a priori knowledge (in fact, there are plenty of reasons to think that this cannot be done). Still, Boghossian maintains that

the synonymy model is correct so far as it goes: it correctly explains the structure of our knowledge of some a priori truths - of those "conceptual" truths, namely, that are transformable into logical truths by the substitution of synonyms for synonyms (2003, 19).

I shall argue, however, that the synonymy model is incapable of explaining knowledge of any a priori truths in the way Boghossian suggests. Certainly, the model can be challenged by arguing that it relies on controversial assumptions, and two influential objections along such lines deserve mention: Firstly, there are familiar Quinean worries concerning whether the notion of synonymy is legitimate at all (cf. Quine 1951), and, less radically, whether there are genuine facts about synonymy which can provide the basis of step (2) of the model (cf. Giaquinto 2008). Secondly, we might worry that even if there are such facts, they cannot be known a priori insofar as this is a matter of empirical linguistics. ${ }^{6}$

These two objections are, however, less than conclusive because they target presuppositions of the synonymy model, which, although controversial,

\footnotetext{
${ }^{5}$ Boghossian is thus conceding an influential point associated with Quine: Synonymy (or definitional abbreviation) cannot explain a priori knowledge (or necessary truth) from scratch (cf. Quine 1936 and Quine 1963).

${ }^{6}$ This might be Boghossian's reason for preferring to focus on idiolects rather than public languages (cf. Boghossian 2012, 233), although at one point he suggests, surprisingly, that it does not matter to him whether the relevant facts about meaning can be known a priori (Boghossian 1996, 386). This is criticized in Margolis and Laurence 2001.
} 
are respectable enough that Boghossian can set these objections aside and remain content with advancing the synonymy model conditionally. My concern is different (although I shall return to considerations related to the second objection): it does not challenge a presupposition of the synonymy model, but highlights a problem that is inherent in the model itself. This problem becomes apparent once we ask: is the proposition expressed by 'All bachelors are unmarried males' the same as the proposition expressed by 'All unmarried males are unmarried males'?

If we say that these sentences express the same proposition, then the model is useless. This is because we are already assuming, at step (6), that we know that all unmarried males are unmarried males. We already know, that is, the proposition expressed by 'All unmarried males are unmarried males', and if this is the same as the proposition expressed by 'All bachelors are unmarried males', then we already have the knowledge which the synonymy model was supposed to explain. Contrary to what Boghossian says, the model does not shed any light on how understanding 'All bachelors are unmarried males' could suffice for 'justified belief in the proposition it expresses' (cf. e.g. 2003, 16). Rather, it presupposes that we are already in possession of such a justification.

If, on the other hand, we say that these two sentences do not express the same proposition, then we run into serious problems with step (2), which states that 'All bachelors are unmarried males' and 'All unmarried males are unmarried males' are synonymous. Surely, we are now entitled to an explanation of how this could be the case if these sentences don't even express the same proposition. Moreover, even if we are prepared to allow that sentences which express different propositions can be synonymous, this only serves to highlight the deeper problem here. For if we entertain this possibility, then what reason do we have to accept step (4) - for accepting, that is, that synonymous sentences must be alike in truth-value?

Boghossian just cites 'conceptual knowledge of the link between mean- 
ing and truth', but the natural way to spell this out is to say that since sentences inherit their truth-values from the propositions they express, sentences expressing the same proposition will always get the same truth-value. If, however, we are prepared to say that the proposition expressed by 'all bachelors are unmarried males' is distinct from that expressed by 'all unmarried males are unmarried males', we need another reason to think that the truth of the latter entails the truth of the former, but no such reason is provided.

The upshot is that the synonymy model is either useless or flawed. It is useless if the propositions are the same, since it then presupposes that we already have the knowledge (or justified belief) which it is meant to explain. It is flawed if the propositions are distinct, since we are then given no reason for thinking that the sentences must be alike in truth-value. This is the dilemma for Boghossian's model as initially formulated.

At this point, one natural way of retreating is to admit that the synonymy model does not explain how grasp of the meaning of a sentence could suffice for being justified in believing the proposition it expresses, but maintain, instead, that it explains how grasping the meaning of a sentence could suffice for being justified in believing the truth of the sentence. We could then concede that the sentences express the same proposition, and, consequently, that there is no new knowledge at step (8), but insist that the model explains the knowledge expressed in step (7).

This, however, is a futile response. For it would now be very misleading to say that the synonymy model explains how understanding a sentence could suffice for being justified in believing that the sentence is true. After all, having granted that the propositions are one and the same, step (6) of the synonymy model amounts to assuming that the reasoner knows that the proposition expressed by the sentence in question is true. And it is hardly significant that we can explain how someone could know the truth of a sentence, given that they know what proposition it expresses and know that this 
proposition is true. 7

It might be said that I am demanding too much from the synonymy model. After all, Boghossian is advancing it, not as a route whereby we in fact arrive at new knowledge, but as something like a proof of concept of his notion of epistemic analyticity. However, the dilemma does not just show that we do not in fact reach new knowledge in this way; it shows that we could not do so. Since we are dealing with epistemic analyticity, a proof of concept would have to be a possible route from knowledge of meaning to knowledge (or at least justification) that we did not already have, which is indeed what Boghossian claims that the synonymy model provides. 8 The above dilemma constitutes a problem for precisely this idea.

To be clear: I do not take this to show that it is impossible to reach a priori knowledge via knowledge of synonymy - only that Boghossian's model sheds no real light on how this could happen. In the remainder of the paper, I shall argue that in order to avoid the dilemma we should have deal with problems that Boghossian's model completely ignores. The upshot is that even if the dilemma can be avoided, Boghossian's model is not the synonymy model we need.

Let us first take a step back: a successful synonymy model needs to show how the notion of synonymy is capable of both making a certain kind of inference (from the truth of one sentence to the truth of another) available to us, and simultaneously yielding new knowledge. The main obstacle is that these aims pull in opposite directions. It is natural to say, for instance, that the inference is unproblematic because synonymous sentences merely express

\footnotetext{
${ }^{7}$ It is, of course, possible to learn that a sentence is true by learning that it is synonymous with some true sentence. We may, for instance, learn that a sentence in a language we don't understand is true by being told that it is synonymous with an English sentence we know to be true. But this is not what Boghossian has in mind since he is concerned with what can be gathered from understanding a sentence. Moreover, it is not at all clear that our knowledge could be a priori in such cases.

${ }^{8}$ As already mentioned, he claims that it 'correctly explains the structure of our knowledge of some a priori truths' (2003, 19), and he also talks of it as showing how grasp of meaning could 'generate entitlement' (2003, 19).
} 
the same piece of knowledge in different ways, but this would undermine the idea that we could ever reach new knowledge in this way.

Now, in order avoid to the above dilemma, we need to make some distinction between what is known (the cognitive content) and the semantic content of a sentence. This is necessary in order to be able to say that two sentences are synonymous, without having to concede that the cognitive content must be the same. In response to the question 'do these sentences express the same propositions?', we can then answer: yes, if we are dealing with semantic content; no, if we are dealing with cognitive content. Propositions have typically been used for both these roles, but a distinction is needed if the synonymy model is to be viable.

We shouldn't, of course, introduce a distinction between semantic and cognitive content just in order to save Boghossian's model. That would be like changing the terrain in order find a use for a map that has turned out to be inadequate. However, some such distinction has been suggested for various reasons. Nathan Salmon, for instance, has argued that we should countenance propositional guises in order to explain how the same semantic content could be simultaneously believed and disbelieved by a perfectly rational and logically competent person (Salmon 1986 , ch. 8 in particular) ${ }^{9}$

Accepting Salmon's suggestion would allow us to make sense of the idea that we could gain knowledge by coming to know the proposition expressed by a sentence $\mathrm{S}$, even if $\mathrm{S}$ is synonymous with $\mathrm{R}$ and we already knew the proposition expressed by R. Properly speaking, what is known is not the proposition as such, but the proposition under a particular guise. Someone could know the proposition expressed by 'All unmarried males are unmarried males' under one guises, and yet gain new knowledge when they come to know the same proposition under a different guise.

However, accepting something such account would not vindicate Boghos-

\footnotetext{
${ }^{9}$ Salmon is advancing a non-Fregean account according to which, e.g., 'Hesperus is now visible' expresses the same semantic content as 'Phosphorus is now visible'. I would like to thank an anonymous referee for suggesting the relevance of Salmon's account here.
} 
sian's model. Introducing propositional guises only allows the synonymy model to deliver on one front (how is this meant give us new knowledge?) at the expense of the other (how do we get to infer the truth of one sentence from the truth of another?).

As I mentioned above, there is already some pressure for Boghossian to say more about how we come to know that expressions are synonymous in the first place. Introducing guises makes this problem much worse, and it makes it unacceptable for some advancing a synonymy model to ignore it. After all, the whole point of introducing propositional guises is to explain how even a perfectly competent speaker could fail to realise that synonymous sentences are synonymous. The guises' primary task is to make the synonymy relation epistemically opaque.

This, moreover, is not just some unwanted excess baggage from Salmon's account. Rather, it is precisely this feature we are trying to exploit. The idea, recall, was to make room for the idea that there can be a difference in cognitive content even if the semantic content is the same, and this must mean that some of the transparency of the synonymy relation is lost. In particular, we can no longer establish whether two sentences are synonymous by inspecting whether there is a difference in the cognitive content.

So, not only does the introduction of something like propositional guises make our epistemic access to facts about synonymy problematic, this appears to be the whole point of introducing them in the present context. It is quite clear, as I see it, that no one who goes down this route in order to offer a working synonymy model can refrain from saying something about our epistemic access to facts about synonymy, and, in particular, the process whereby we recognise that we are dealing with the same semantic content, but under different guises. We cannot deliberately introduce a gap between the cognitive contents of synonymous sentences, and then refuse to say anything about how the synonymy model manages to bridge that gap - especially in the context of explaining epistemic analyticity. 
Let us consider the problem in the context of Boghossian's example. Here the idea would presumably be that 'bachelor' and 'unmarried male', though synonymous, present the same concept under different guises, thereby allowing that the cognitive content of a sentence could change under substitution. The problem, now, is that if we really are to take seriously the idea that there is such a difference in cognitive content here, then we are also owed an account of how an epistemic agent which goes through the reasoning of Boghossian's model gets to be so confident that substituting one for the other is guaranteed to preserve truth.

Boghossian's model has nothing to say about this, and so we are essentially in the following situation: something like propositional guises is meant to provide us with an epistemic gap which the synonymy model could then help us bridge. But having introduced this gap, we now see that there is actually nothing in that model which helps us bridge it. This is why I claim that, once we make the distinction between semantic and cognitive content needed to avoid the dilemma, Boghossian's model sheds no real light on how synonymy could provide a route to a priori knowledge.10 Avoiding the above dilemma in this way is not to fix Boghossian's model, but to concede that an entirely different model is needed.

The underlying problem is that Boghossian's model has nothing to say about the main obstacle that a synonymy model needs to overcome: that of explaining how synonymy could both provide a route to new knowledge, and make the required inference from the truth of one sentence to the truth of another available to us. A proper synonymy model would be one which successfully negotiates these apparently conflicting aims, and reconciles the transparency needed to make the inference available to epistemic agents with the opacity needed to make room for new knowledge. Unfortunately, Boghossian's model is not that model.

\footnotetext{
${ }^{10}$ The problem, then, does not concern the appeal to Salmon's guises in particular, but the general idea of introducing a gap in cognitive content in order to allow for new knowledge.
} 


\section{References}

Ayer, A. J. (1936a). Language, Truth \& Logic. London: Victor Gollancz Ltd.

- (1936b). "Truth by convention: a symposium by A. J. Ayer, C. H. Whiteley, M. Black". In: Analysis 4, pp. 17-22.

Boghossian, P. (1996). "Analyticity reconsidered". In: Nô̂s 30, pp. 360-91.

- (2003). "Epistemic analyticity: a defense". In: Grazer Philosophische Studien 66 .

- (2012). "Inferentialism and the epistemology of logic: reflections on Casalegno and Williamson". In: Dialectica 66, pp. 221-36.

Giaquinto, M. (2008). "The linguistic view of a priori knowledge". In: Philosophy 83, pp. 89-111.

Margolis, E. and S. Laurence (2001). "Boghossian on analyticity". In: Analysis 61, pp. 293-302.

Quine, W. V. (1936). "Truth by convention". In: Philosophical Essays for A. N. Withehead. Ed. by O. H. Lee. New York: Longmans, pp. 90-124.

- (1951). "Two dogmas of empiricism". In: The Philosophical Review 60, pp. $20-43$.

- (1963). "Carnap and logical truth". In: The Philosophy of Rudolf Carnap. Ed. by P. A. Schlipp. Library of Living Philosophers. LaSalle, Ill.: Open Court, pp. 385-406.

Salmon, N. (1986). Frege's Puzzle. Cambridge, Mass.: The MIT Press. 